\title{
The Utility of Essential Functions in Clinical Laboratory Science Programs
}

\author{
MARIA E. DELOST, TERESA S. NADDER
}

OBJECTIVE: Essential functions (EF) define the nonacademic criteria used to determine an individual's qualifications for admission and capabilities of performing in the classroom and laboratory with or without reasonable accommodations. Directors of NAACLS approved and accredited programs were surveyed to investigate their knowledge and perceptions of EF and associations with disabilities and student behaviors.

DESIGN: This was a non-experimental survey consisting of questions related to the use of essential functions (EF) and student behaviors in NAACLS laboratory programs. SurveyMonkey was used to electronically provide the survey of 33 questions to 564 NAACLS programs.

RESULTS: Descriptive statistics were reported as aggregate data with a response rate of 267 (47.3\%). EF are utilized in $95.5 \%$ of the programs; however, only $38.6 \%$ of the participants responded that $\mathrm{EF}$ are required by both the ADA and NAACLS. A student had never been dismissed based on EF in $80.0 \%$ of the programs. Many programs have been successful in mentoring students with disabilities to successful completion. Hearing impairment was the most reported disability ( $30.0 \%)$. Participants felt most comfortable referring students for academic coaching (96.2\%) when compared to medical concerns (86.5\%), and psychological concerns $(82.7 \%)$.

CONCLUSIONS: While most programs utilized EF, many program directors were not aware that EF are required by both NAACLS and the ADA. Programs have successfully instructed and graduated students with a variety of disabilities and generally feel comfortable in referring students for assistance. Concerns with inappropriate behaviors present unique, generational challenges to faculty.
ABBREVIATIONS: EF-Essential Functions, ADAAmerican with Disabilities Act, NAACLS-National Accrediting Agency for Clinical Laboratory Sciences

INDEX TERMS: Essential Functions, Documented Disability, American with Disabilities Act ,Reasonable Accommodation, Student behaviors

Clin Lab Sci 2011;24(4):Suppl 4-21

Maria E. Delost, PhD, MT(ASCP), Youngstown State University, Department of Health Professions, Youngstown, $\mathrm{OH}$

Teresa S. Nadder, PhD, MLS(ASCP) ${ }^{C M}$, Department of Clinical Laboratory Sciences, Virginia Commonwealth University, Richmond, VA

Address for Correspondence: Maria Delost, PhD, Youngstown State University, Professor and Director of Clinical Laboratory Programs, Department of Health Professions, Youngstown, $\mathrm{OH}$ 44555, 330-941-1761, medelost@ysu.edu

\section{INTRODUCTION}

Essential functions define the nonacademic criteria used to determine whether an individual qualifies for admission and is capable of performing in the classroom and laboratory with or without reasonable accommodations. Originally mandated by the National Accrediting Agency for Clinical Laboratory Sciences (NAACLS) in the 1986 Essentials, accredited and approved programs are required to establish, publish and provide these criteria to prospective students. ${ }^{1,3}$ The essential function requirement was developed in response to the Rehabilitation Act (1973) and the Americans with Disabilities Act (1990) to insure that academic programs develop, publish and make available to the public and prospective students these taskoriented physical and behavioral standards in which 


\section{RESEARCH AND REPORTS}

students must engage to successfully complete a laboratory program. ${ }^{2}$ NAACLS recommends that the Essential Functions address, at a minimum, the following areas: observation, communication, psychomotor skills, intellectual and cognitive abilities, behavioral and social attributes, ethical standards, and academic performance. ${ }^{3}$

The Americans with Disabilities Act of 1990 (ADA) protects qualified individuals with disabilities in the workplace. Federal Law, under Section 504 of the Rehabilitation Act of 1973 requires that no otherwise qualified person with a disability in the United States shall, solely by reason of disability, be denied the benefits of, be excluded from participation in, or be subjected to discrimination under any program or activity receiving federal financial assistance. Those postsecondary educational institutions that receive any federal financial assistance must comply with Section 504. Thus, clinical laboratory science educational programs are responsible for providing education without regard to disability while assuring that academic and technical standards are met. All students admitted to such a program must possess the skills outlined in the essential functions with or without reasonable accommodations to complete the requirements of the program.

The physical and mental attributes necessary to perform required essential functions (EF) play an important role in the education of students enrolled in health profession programs. These nonacademic elements in the education process contribute significantly to the student's success or failure in navigating through the pathways of education, including those found in the didactic, laboratory and clinical arenas. Additionally, criteria must be followed in order to remain compliant with the American with Disabilities Act (ADA) as well as accreditation standards outlined by the National Accrediting Agency for Clinical Laboratory Sciences (NAACLS). ${ }^{1,2,4}$ EF can be utilized as a mechanism for self-elimination of individuals from admission to a program or subsequent dismissal if the EF cannot be met. However, the set of EF developed by a given academic program may be inadequate for capturing all nonacademic attributes that may hinder students' progression in the program. For example, inappropriate or disruptive behaviors may result in a student's dismissal from a laboratory program.
Published literature on the implementation and use of EF in allied health and nursing programs is limited. Shortly after the ADA of 1990 was instituted, a study examined the prevalence of $\mathrm{EF}$ in bachelor of science in nursing (BSN) programs (Davidson, 1994). ${ }^{5}$ In this study of 164 programs, results indicated that only $14 \%$ used an EF tool as an admission consideration. Respondents were conflicted, as how to balance the safety of patients with the rights of the disabled to participate in nursing programs. Although the ADA has now been in existence for over 20 years and while educators are aware of its implications, the connection to essential functions is not always apparent. Today EF are required as an accreditation standard for many allied health programs, including nursing, laboratory sciences, physical therapy and respiratory care as a result of the legislation in the ADA. However, other accrediting agencies, such as CoAEMSP, the Committee on Accreditation of Educational Programs for the Emergency Medical Services Professions, do not specifically require an essential function tool in the educational accreditation process but instead requires specific essential functions developed by their national registry.

The purpose of this study was to investigate the knowledge and experience of program officials in NAACLS accredited and approved programs related not only to essential functions and ADA but also to student health, student behaviors, and available student services. An additional research question relates to the implementation of the EF document and how it is used as a tool to screen and evaluate program applicants and enrolled students. We also examined the prevalence of specific student behaviors and associated consequences, as identified by program directors. The prevalence and use of student services to assist students in problematic areas were also assessed.

\section{METHODS}

The study design was a non-experimental survey consisting of questions related to the knowledge and use of essential functions (EF) in a NAACLS accredited or approved clinical laboratory sciences programs. SurveyMonkey was used to electronically provide the survey of 33 questions to 564 NAACLS programs. Questions also probed the incidence and types of students with disabilities who have completed these programs, types of student services available to an 
institution and those utilized for student referrals, and incidence of inappropriate student behaviors. Demographic data on program type, location, annual graduate numbers, and characteristics of the program director were also collected. IRB approval for the study was received by Youngstown State University. Descriptive statistics were reported as aggregate data. Using cross tabs, responses for specific program types and locations were analyzed and reported as percentage results.

\section{RESULTS}

A summary of the survey questions with pertinent results is presented in Tables 1-3. Demographic summaries are shown in Figures 1 and 2. A discussion of relevant findings in presented below.
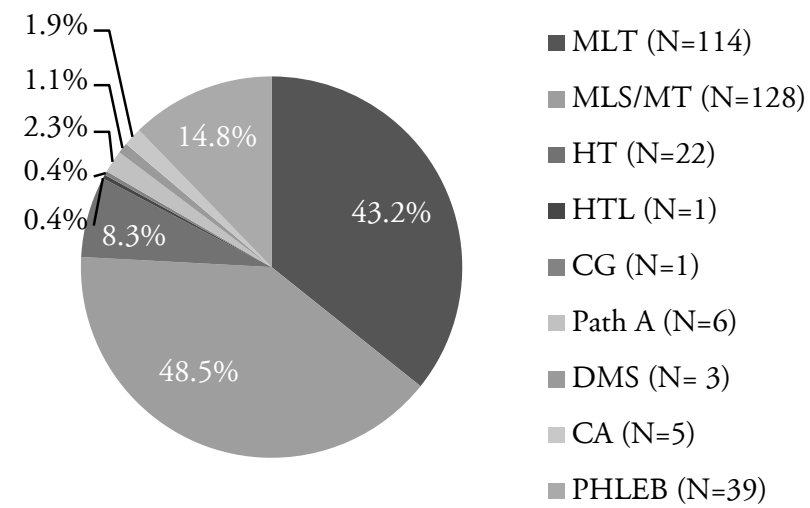

Figure 1. Program Types

Demographics. The response rate from the electronic survey was $47.3 \%$, which included 267 responses from program directors. A total of 319 laboratory science programs accredited or approved by NAACLS were included in the survey as some program directors responded for more than one program within their institution. Figures 1 and 2 show a summary of the demographics for the programs that responded to the survey. The majority of the respondents were directors of medical laboratory technician, MLT $(\mathrm{N}=114)$, and medical laboratory scientist, MLS/MT ( $=128)$, programs. Other program responses included histotechnician, HT $(\mathrm{N}=22)$, histotechnologist, HTL $(\mathrm{N}=1)$, cytogenetics, $\mathrm{CG}(\mathrm{N}=1)$, pathologists' assistant, Path A $(\mathrm{N}=6)$, diagnostic molecular scientist, DMS $(\mathrm{N}=3)$, clinical laboratory assistant, $\mathrm{CA}(\mathrm{N}=5)$, and phlebotomy, PHLEB $(\mathrm{N}=39)$ programs that were included in the survey (Figure 1). Approximately 37\% of the programs were located in community colleges, $25 \%$ in four-year universities, and $25 \%$ in hospital laboratories as shown in Figure 2. There were 26.9\% of the programs that reported $7-10$ graduates per year while $20.5 \%$ reported $11-15$ graduates per year. The highest degree reported from the majority of the respondents was the master's degree (75.4\%); 14.8\% held doctorate degrees. Forty percent of the respondents had 10 years or less of experience, and 30.6\% reported over 20 years of experience.
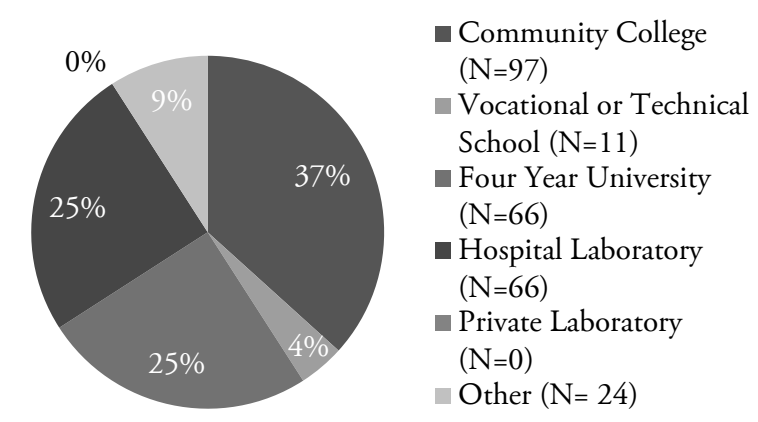

Figure 2. Program Location ( $\mathrm{N}=264)$

Knowledge of NAACLS and ADA Requirements for Essential Functions (Table 1). When asked if EF are required by NAACLS, the Americans Disabilities Act (ADA), both NAACLS and ADA, or neither, only $38.6 \%$ of the participants responded to the question correctly that an EF policy is required by both NAACLS and ADA (1-A). A higher percentage of participants from community college systems (49.5\%), MLT programs (43.9\%) and HT/HTL programs $(47.8 \%)$ chose the correct answer in comparison to programs based in hospital laboratories (36.4\%), universities (33.3\%), or MLS/MT programs (33.6\%). In addition, over $80 \%$ of the total respondents agreed with the incorrect statement that educational programs are required to ensure that students have the ability to perform skills related to essential functions in the work place once hired. (1-B). Only about $21 \%$ of respondents from university and community college programs each and $10.6 \%$ of those from hospital based programs disagreed with this statement.

Implementation of Essential Functions. Essential functions are distributed to applicants or prospective students in $95.5 \% \quad(\mathrm{~N}=255)$ of the programs as indicated by the responses from the survey (1-C). A signed statement or attestation that the student read and 
Table 1. Essential Functions Survey Results by Program Type and Location. Knowledge and Implementation of Essential Functions

1-A. Essential Functions are required by

\section{TOTAL}

$\%$

NAACLS $\quad 49$

ADA 4

NAACLS\& ADA 39

Neither- only 8

for suitability

\section{PROGRAM TYPE}

MLT

(\%)

44.7

2.6

43.9

8.8

\section{MLS/MT}

(\%)

53.1

3.1

33.6

10.2
HT/HTL

(\%)

$34.8 \%$

$8.7 \%$

$47.8 \%$

$8.7 \%$
PHLEB

(\%)

43.5

10.3

35.9

10.3
PROGRAM LOCATION

HOSP CC UNIV

(\%) (\%) (\%)

$\begin{array}{lll}51.5 & 42.2 \quad 51.5\end{array}$

$\begin{array}{lll}4.5 & 3.1 & 1.5\end{array}$

$36.4 \quad 49.5 \quad 33.3$

$\begin{array}{lll}7.6 & 5.2 & 13.5\end{array}$

1-B. As educators, it is our responsibility to ensure that students in our programs can perform essential functions in the work place once hired.

\begin{tabular}{|c|c|c|c|c|c|c|c|c|}
\hline & \multirow{2}{*}{$\begin{array}{c}\text { TOTAL } \\
\%\end{array}$} & \multicolumn{4}{|c|}{ PROGRAM TYPE } & \multicolumn{3}{|c|}{ PROGRAM LOCATION } \\
\hline & & $\begin{array}{c}\text { MLT } \\
(\%)\end{array}$ & $\begin{array}{c}\text { MLS/MT } \\
(\%)\end{array}$ & $\begin{array}{c}\mathrm{HT} / \mathrm{HTL} \\
(\%)\end{array}$ & $\begin{array}{c}\text { PHLEB } \\
(\%)\end{array}$ & $\begin{array}{c}\text { HOSP } \\
(\%)\end{array}$ & $\begin{array}{l}\text { CC } \\
(\%)\end{array}$ & $\begin{array}{c}\text { UNIV } \\
(\%)\end{array}$ \\
\hline Agree Strongly & 43.8 & 35.1 & 47.7 & 56.5 & 46.2 & 59.1 & 39.1 & 34.8 \\
\hline Agree & 38.2 & 43.0 & 36.7 & 26.1 & 43.6 & 30.3 & 41.2 & 43.9 \\
\hline Disagree & 13.5 & 15.8 & 13.3 & 17.4 & 5.1 & 9.1 & 15.5 & 16.8 \\
\hline Disagree Strong & ly 4.5 & 6.1 & 2.3 & 0.0 & 5.1 & 1.5 & 6.2 & 4.5 \\
\hline
\end{tabular}

1-C. Essential functions are distributed to applicants or prospective students in our program.

\begin{tabular}{|c|c|c|c|c|c|c|c|c|}
\hline \multirow{2}{*}{\multicolumn{2}{|c|}{$\begin{array}{c}\text { TOTAL } \\
\%\end{array}$}} & \multicolumn{4}{|c|}{ PROGRAM TYPE } & \multicolumn{3}{|c|}{ PROGRAM LOCATION } \\
\hline & & $\begin{array}{c}\text { MLT } \\
(\%)\end{array}$ & $\begin{array}{c}\text { MLS/MT } \\
(\%)\end{array}$ & $\begin{array}{c}\mathrm{HT} / \mathrm{HTL} \\
(\%)\end{array}$ & $\begin{array}{c}\text { PHLEB } \\
(\%)\end{array}$ & $\begin{array}{c}\text { HOSP } \\
(\%)\end{array}$ & $\begin{array}{l}\text { CC } \\
(\%)\end{array}$ & $\begin{array}{c}\text { UNIV } \\
(\%)\end{array}$ \\
\hline Yes & 95.5 & 94.7 & 95.3 & 95.7 & 97.4 & 97.0 & 94.8 & 95.5 \\
\hline No & 4.5 & 5.3 & 4.7 & 4.3 & 2.6 & 3.0 & 5.2 & 4.5 \\
\hline
\end{tabular}

1-D. We require students to acknowledge receipt and understanding of essential functions through a signed statement or attestation after they have read the essential function policy of our program.

TOTAL

Yes

No

$\% \quad$ MLT

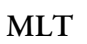

$(\%)$

94.4

5.6
PROGRAM TYPE MLS/MT

(\%)

98.4

1.6
HT/HTL

(\%)

91.3

8.7
PHLEB

$(\%)$

89.7

10.3
PROGRAM LOCATION

HOSP CC UNIV

$(\%) \quad(\%) \quad(\%)$

$\begin{array}{lll}98.5 & 89.7 \quad 97\end{array}$

$\begin{array}{lll}1.5 & 10.3 \quad 3\end{array}$

1-E. Our program discusses/reviews essential functions with new students and discusses any concerns with the student.

\begin{tabular}{|c|c|c|c|c|c|}
\hline \multirow{3}{*}{ 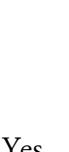 } & \multirow{2}{*}{$\begin{array}{c}\text { TOTAL } \\
\%\end{array}$} & \multicolumn{4}{|c|}{ PROGRAM TYPE } \\
\hline & & $\begin{array}{c}\text { MLT } \\
(\%)\end{array}$ & $\begin{array}{c}\text { MLS/MT } \\
(\%)\end{array}$ & $\begin{array}{c}\text { HT/HTL } \\
(\%)\end{array}$ & $\begin{array}{c}\text { PHLEB } \\
(\%)\end{array}$ \\
\hline & 83.1 & 87.7 & 81.3 & 82.6 & 87.2 \\
\hline No & 17.0 & 12.3 & 18.7 & 17.4 & 12.8 \\
\hline
\end{tabular}

\begin{tabular}{ccc}
\multicolumn{3}{c}{ PROGRAM LOCATION } \\
HOSP & CC & UNIV \\
$(\%)$ & $(\%)$ & $(\%)$ \\
85.0 & 84.0 & 77 \\
15.0 & 16 & 23
\end{tabular}

1-F. A student enrolled in our program was advised to seek another education program based on concerns related to essential functions.

\section{TOTAL \\ $\%$}

Yes

1-3 times

Never
30.3

69.7
PROGRAM TYPE

MLT

(\%)

41.2

58.8

\section{MLS/MT}

(\%)

21.9

78.1
HT/HTL

(\%)

52.2

47.8
PHLEB

(\%)

30.8

69.2
PROGRAM LOCATION

HOSP CC UNIV

$(\%) \quad(\%)$

$\begin{array}{lll}10.6 & 39.2 & 34.8 \\ 89.4 & 60.8 & 65.2\end{array}$ 
Table 1. (Continued)

1-G. We have removed a student from our program based on problems in performances or tasks outlined in our essential functions document.

\section{TOTAL}

$\%$

Yes

1-3 times

Never
PROGRAM TYPE

MLT

(\%)

27.2

72.8
MLS/MT

(\%)

16.4

83.6
HT/HTL

(\%)

21.7

78.3
PHLEB

(\%)

30.8

69.2
PROGRAM LOCATION

HOSP CC UNIV

(\%) (\%) (\%)

$\begin{array}{lll}9.1 & 24.7 & 28.8\end{array}$

$\begin{array}{lll}90.9 & 75.3 \quad 71.2\end{array}$

1-H. Our program is reluctant to fully enforce the requirements outlined in our essential functions because of fears of violating ADA regulations.

TOTAL

$\% \quad$ MLT

Agree Strongly 1.5

Agree $\quad 16.9$

Disagree $\quad 56.9$

Disagree Strongly 17.2

NA - No $\quad 7.5$

disabilities office
PROGRAM TYPE

MLS/MT HT/HTL PHLEB

$(\%) \quad(\%) \quad(\%)$

0.8

5.5

60.2

23.4

10.2

0

17.4

65.2

13.1

4.3
$(\%)$
2.6

23.1

56.4

15.4

2.6
PROGRAM LOCATION

HOSP CC UNIV

(\%) (\%) (\%)

$\begin{array}{lll}0 & 2.1 & 3.0\end{array}$

$\begin{array}{lll}6.1 & 26.8 \quad 10.6\end{array}$

$\begin{array}{lll}56.1 & 58.1 \quad 60.6\end{array}$

$19.7 \quad 10.3 \quad 24.2$

$18.2 \quad 2.1 \quad 1.5$

1-I. Our disabilities office has encouraged us to admit a student into our program even when we had concerns about limitations identified through our essential functions or physical examination documents.

TOTAL

$\%$

Agree strongly $\quad 4.1$

Agree $\quad 9.7$

Disagree $\quad 45.3$

Disagree Strongly 20.3

NA - No $\quad 20.6$

disabilities office
PROGRAM TYPE

MLT

(\%)

5.3

14.9

57.0

14.9

7.9
MLS/MT

(\%)

1.6

4.7

36.7

24.2

32.8

\section{$\mathrm{HT} / \mathrm{HT}$}

$(\%)$
4.3

17.4

52.2

17.4

8.7
PHLEB

(\%)

7.7

23.1

46.2

12.8

20.3
PROGRAM LOCATION

HOSP CC UNIV

(\%) (\%) (\%)

$\begin{array}{lll}1.5 & 7.2 & 3.0\end{array}$

$\begin{array}{lll}3.0 & 15.4 & 9.1\end{array}$

$\begin{array}{lll}27.3 & 56.7 & 45.5\end{array}$

$\begin{array}{lll}12.1 & 15.5 & 37.9\end{array}$

$\begin{array}{lll}56.1 & 5.2 \quad 4.5\end{array}$

1-J. Students are required to complete a physical examination as an admission requirement to our institution. TOTAL

Yes $\quad 54.7$

No $\quad 43.4$

Unsure
PROGRAM TYPE

MLT

(\%)

50.0

49.1

0.9
MLS/MT

(\%)

57.0

41.4

1.6
$\mathrm{HT} / \mathrm{HTL}$

$(\%)$

70.0

30.0

0.0
PHLEB

(\%)

48.7

48.7

2.6
PROGRAM LOCATION

HOSP CC UNIV

(\%) (\%) (\%)

$\begin{array}{lll}68.2 & 50.5 & 47.0\end{array}$

$30.3 \quad 48.5 \quad 50.0$

$\begin{array}{lll}1.5 & 1.0 & 3.0\end{array}$
Key :

MLT $=$ Medical Laboratory Technician, $\mathrm{N}=114$

MLS/MT $=$ Medical Laboratory Science/Medical Technology, N=128

$\mathrm{HT} / \mathrm{HTL}=$ Histotechnician $(\mathrm{N}=22) /$ Histotechnologist $(\mathrm{N}=1), \mathrm{N}=23$

PHLEB = Phlebotomy, N=39

understood the EF policy of the program (1-D) is required by $94.4 \%(\mathrm{~N}=252)$ of the programs, with the lowest percentage observed in programs in community colleges $(89.7 \%)$ and in phlebotomy programs $(89.7 \%)$. Fewer number of programs $(\mathrm{N}=222)$ indicated that the EF policy (1-E) is discussed with newly admitted students. Community college programs (84.0\%), phlebotomy programs (87.2\%) and hospital-based programs $(85.0 \%)$ review the EF policy more often with
HOSP $=$ Hospital Based Program, N= 66 $\mathrm{CC}=$ Community College Program, $\mathrm{N}=97$ UNIV= University Based Program, N=66

their students in comparison to university-based programs $(77.0 \%)$. Further, $30 \%$ of the respondents indicated that at least once, a student was advised to seek another educational program based on concerns related to essential functions (1-F), with the highest percentage from the community college $(39.2 \%)$ and HT/HTL (52.2\%) programs. Approximately 20\% of the total respondents reported dismissing 1-3 students from the program based on essential functions 


\section{RESEARCH AND REPORTS}

requirements (1-G). The highest percentages for dismissing students based on the EF requirements were from phlebotomy (30.8\%) and university based (28.8\%) programs.

Fewer than $20 \%$ of the respondents indicated that their program is reluctant to fully enforce the requirements outlined in their EF policy because of fears of violating ADA regulations (1-H). Community colleges (28.9\%) and MLT programs $(30.7 \%)$ concurred most frequently with this statement. In general, programs were not encouraged to admit students into programs (1-I) when there were concerns about the applicant's limitations as identified through the EF tool or physical assessment with only $13.8 \%$ of the respondents agreeing with this statement. However, respondents from phlebotomy programs $(25.1 \%)$ and MLT programs $(20.2 \%)$ agreed more frequently with this statement than those from other programs, especially MLS/MT (6.3\%).

Student Behaviors (Table 2). Approximately $42 \%$ of the respondents had concerns of inappropriate student behavior in the classroom (2-A), with $31.8 \%$ reporting an increase in this behavior in the last five years (2-B). Respondents reported that $26.5 \%$ personally felt threatened by a student's behavior (2-C). Threatening student behavior was reported the least by hospitalbased programs $(12.1 \%)$ and highest in phlebotomy programs $(35.9 \%)$, the community college setting (35.1\%), and by MLT programs (32.5\%). Inappropriate behavior in the clinical sites (2-D-E) resulted in removal from the rotation or probation of at least one student in $42.3 \% \%$ and $40.1 \%$, respectively, of the programs surveyed. Hospital based programs placed the lowest percentage of students on probation $(24.2 \%)$ when compared to other programs (2-E). Programs in community colleges $(58 \%)$ and phlebotomy programs $(64.1 \%)$ had removed students from rotations more often when compared to the other programs. However, greater that $86 \%$ of the programs received institutional support with student behavioral concerns (2-F).

Student Services (Table 3). The following services (3-A) are available to students at the respondents' institutions: disability (74.9\%), mental/psychological (73.4\%), medical/student health (55.1\%), and academic tutoring (84.6\%). Students with the following disabilities (3-B) were reported to successfully complete the respondents' programs: vision $(16.9 \%)$, hearing $(30.0 \%)$, mobility (19.9\%), and mental/psychological (23.2\%). Other types of disabilities $(46.1 \%)$ reported included learning disabilities, attention deficit disorder, communication problems, and the use of only one arm or hand.

More than $96 \%$ of the respondents felt comfortable referring students to student services for academic coaching, $86.5 \%$ for medical services, and $82.7 \%$ for counseling or psychological testing. Indeed, within the last two years $72.7 \%$ of the respondents recommended academic tutoring to their students, $52.1 \%$ reported sent students to psychological/mental health services, $35.6 \%$ to student health, and $34.1 \%$ to the institution's disability office.

\section{DISCUSSION}

In our study, only $38.6 \%$ of the respondents correctly indicated that an EF document is both an accreditation and $\mathrm{ADA}$ requirement for clinical laboratory science programs. Most respondents incorrectly responded that $\mathrm{EF}$ are only a NAACLS requirement to meet accreditation standards. While essential functions are required by accreditation for some allied health programs, they are not universally mandatory for all programs. To meet accreditation standards and ADA requirements for essential functions, students of clinical laboratory science programs must be informed of the program's physical and behavioral requirements and that these requirements must be met to succeed in the program. These task-oriented expectations must be developed, published and made available to all students, prospective applicants, and the general public. Essential functions must be applied objectively and consistently to all students and include criteria related to vision, communication skills, physical and motor skills, psychological stability, and behavioral, intellectual and integrative skills. These functions must be either possessed by students or attained by students while in the program and are written with outcome based verbs to delineate the required attributes. It is also important to note that it is a common misconception that $\mathrm{EF}$ must reflect those attributes necessary for successful employment when in fact the EF are applicable only to the educational program.

Another method to ascertain if an applicant possesses the required health and safety to meet the program essential functions is through a physical examination. While not an accreditation requirement, a physical 
Table 2. Student Behaviors Survey Results by Program Type and Location

2-A. We have had concerns with inappropriate behavior in the classroom which might lead to aggressiveness or violence.

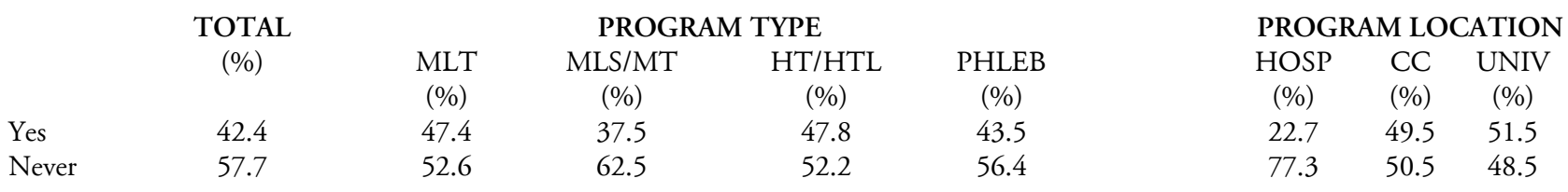

2-B. There has been an increase in the amount of inappropriate behavior by students in the last five years.

\section{TOTAL}

(\%)

Agree strongly $\quad 3.0$

Agree $\quad 28.8$

Disagree $\quad 52.8$

Disagree strongly 15.4

\section{PROGRAM TYPE}

$\begin{array}{cccc}\text { MLT } & \text { MLS/MT } & \text { HT/HTL } & \text { PHLEB } \\ (\%) & (\%) & (\%) & (\%) \\ 2.6 & 1.6 & 8.7 & 5.1 \\ 37.7 & 21.9 & 30.5 & 28.2 \\ 51.8 & 56.2 & 39.1 & 61.6 \\ 7.9 & 20.3 & 21.7 & 5.1\end{array}$

PROGRAM LOCATION

HOSP CC UNIV

(\%) (\%) (\%)

$\begin{array}{lll}0 & 3.1 & 3.0\end{array}$

$\begin{array}{lll}16.7 & 37.1 & 28.8\end{array}$

$48.5 \quad 53.6 \quad 60.6$

$34.8 \quad 6.2 \quad 7.6$

2-C. I have personally felt threatened by a student's inappropriate behavior.

\begin{tabular}{|c|c|c|c|c|c|c|c|c|}
\hline & TOTAL & & PROGF & ГYPE & & PROG & M LO & ATION \\
\hline & $(\%)$ & MLT & MLS/MT & $\mathrm{HT} / \mathrm{HTL}$ & PHLEB & HOSP & $\mathrm{CC}$ & UNIV \\
\hline & & $(\%)$ & $(\%)$ & $(\%)$ & $(\%)$ & $(\%)$ & $(\%)$ & (\%) \\
\hline Agree strongly & 3.7 & 5.3 & 2.3 & 13.0 & 5.1 & 1.5 & 5.2 & 4.5 \\
\hline Agree & 22.9 & 27.2 & 18.0 & 17.4 & 30.8 & 10.6 & 29.9 & 27.3 \\
\hline Disagree & 44.6 & 47.3 & 43.8 & 34.8 & 36.7 & 31.8 & 47.4 & 45.5 \\
\hline Disagree strong & ly 28.8 & 20.2 & 35.9 & 34.8 & 33.3 & 56.1 & 17.5 & 22.7 \\
\hline
\end{tabular}

2-D. We have had to remove a student from a clinical site or rotation based on his/her inappropriate behavior.

\begin{tabular}{|c|c|c|c|c|c|c|c|c|}
\hline & \multirow{2}{*}{$\begin{array}{c}\text { TOTAL } \\
(\%)\end{array}$} & \multicolumn{4}{|c|}{ PROGRAM TYPE } & \multicolumn{3}{|c|}{ PROGRAM LOCATION } \\
\hline & & $\begin{array}{c}\text { MLT } \\
(\%)\end{array}$ & $\begin{array}{c}\text { MLS/MT } \\
(\%)\end{array}$ & $\begin{array}{c}\mathrm{HT} / \mathrm{HTL} \\
(\%)\end{array}$ & $\begin{array}{c}\text { PHLEB } \\
(\%)\end{array}$ & $\begin{array}{c}\text { HOSP } \\
(\%)\end{array}$ & $\begin{array}{l}\text { CC } \\
(\%)\end{array}$ & $\begin{array}{c}\text { UNIV } \\
(\%)\end{array}$ \\
\hline Yes & 42.3 & 54.4 & 29.7 & 56.5 & 64.1 & 12.1 & 58.0 & 45.5 \\
\hline Never & 57.7 & 45.6 & 70.3 & 43.5 & 35.9 & 87.9 & 42.0 & 54.5 \\
\hline
\end{tabular}

2-E. A student has been placed on probation based on his/her inappropriate behavior in the classroom or clinical site. TOTAL

(\%)

Yes

Never
PROGRAM TYPE

$\begin{array}{cccc}\text { MLT } & \text { MLS/MT } & \text { HT/HTL } & \text { PHLEB } \\ (\%) & (\%) & (\%) & (\%) \\ 47.4 & 33.6 & 56.5 & 51.3 \\ 52.6 & 66.4 & 43.5 & 48.7\end{array}$

PROGRAM LOCATION

HOSP CC UNIV

(\%) (\%) (\%)

$24.2 \quad 45.4 \quad 43.9$

$75.8 \quad 54.6 \quad 56.1$

2-F. My institution supports me when I have concerns with a student's inappropriate behavior.

\begin{tabular}{|c|c|c|c|c|c|c|c|c|}
\hline & TOTAL & & PROG & ГYPE & & PROG & M LC & ATION \\
\hline & $(\%)$ & $\begin{array}{c}\text { MLT } \\
(\%)\end{array}$ & $\begin{array}{c}\text { MLS/MT } \\
(\%)\end{array}$ & $\begin{array}{c}\mathrm{HT} / \mathrm{HTL} \\
(\%)\end{array}$ & $\begin{array}{c}\text { PHLEB } \\
(\%)\end{array}$ & $\begin{array}{c}\text { HOSP } \\
(\%)\end{array}$ & $\begin{array}{l}\text { CC } \\
(\%)\end{array}$ & $\begin{array}{l}\text { UNIV } \\
(\%)\end{array}$ \\
\hline Agree strongly & 33.0 & 32.4 & 32.8 & 26.1 & 33.3 & 36.3 & 39.2 & 27.3 \\
\hline Agree & 53.2 & 54.5 & 52.4 & 43.5 & 61.6 & 45.5 & 48.4 & 62.2 \\
\hline Disagree & 2.6 & 2.6 & 2.3 & 13.0 & 5.1 & 1.5 & 3.1 & 4.5 \\
\hline Disagree Strongl & ly 1.9 & 2.6 & 0.8 & 4.4 & 0 & 0 & 2.1 & 1.5 \\
\hline NA & 9.4 & 7.9 & 11.7 & 13.0 & 0 & 16.7 & 7.2 & 4.5 \\
\hline
\end{tabular}

Key :

MLT $=$ Medical Laboratory Technician, $N=114$

MLS/MT = Medical Laboratory Science/Medical Technology, N=128

$\mathrm{HT} / \mathrm{HTL}=$ Histotechnician $(\mathrm{N}=22) /$ Histotechnologist $(\mathrm{N}=1), \mathrm{N}=23$

PHLEB = Phlebotomy, $\mathrm{N}=39$
HOSP $=$ Hospital Based Program, N= 66

$\mathrm{CC}=$ Community College Program, N=97

UNIV= University Based Program, N=66 
Table 3. Student Services Survey Results by Program Type and Location

3-A. My institution has the following services available for students. Mark all that apply.

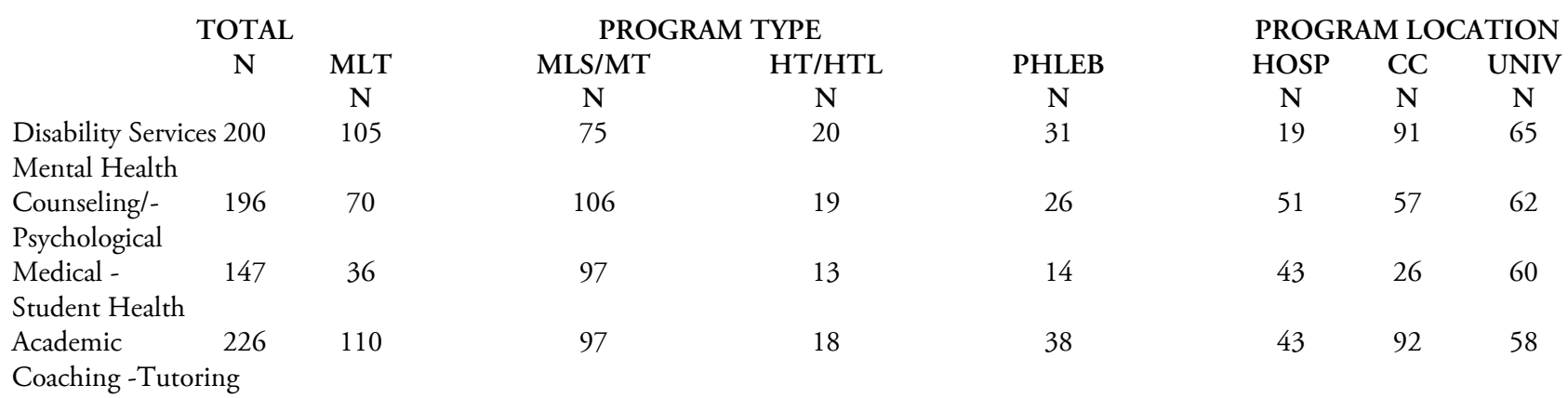

3-B. I have recommended the following services to my students in the past two years. Mark all that apply.

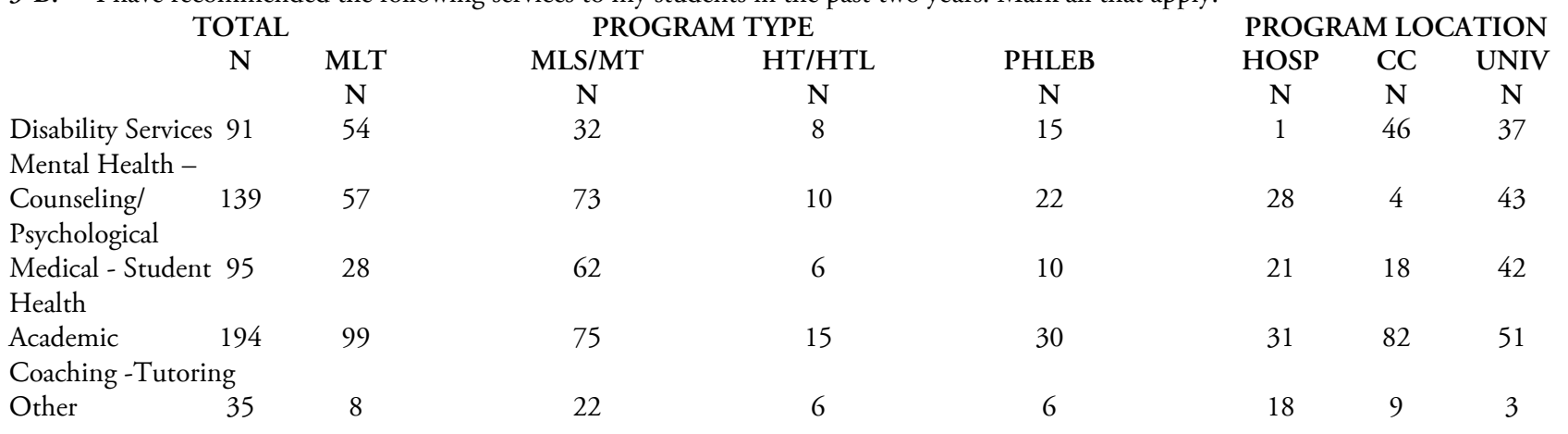

Key :

MLT $=$ Medical Laboratory Technician, $\mathrm{N}=114$

MLS/MT = Medical Laboratory Science/Medical Technology, N=128

$\mathrm{HT} / \mathrm{HTL}=$ Histotechnician $(\mathrm{N}=22) /$ Histotechnologist $(\mathrm{N}=1), \mathrm{N}=23$

PHLEB = Phlebotomy, $\mathrm{N}=39$

assessment is useful in evaluating the health status of potential students. A general health history, health screen, and immunization status will assist the program to determine if the applicant's health will permit them to meet the essential functions of the program. Physical assessments were required by $54.7 \%$ of the programs that participated in the study.

If a deficiency in meeting an essential function is identified in a student or applicant, the disability must be documented through the appropriate agency or department at the institution, for example, at the academic disability services office or other student services office. If the student has a documented disability, he or she may request modifications, accommodations, or auxiliary aids. ${ }^{3}$ In our study, only a small percentage of the respondents indicated that they advised a student to seek another program based on the
HOSP $=$ Hospital Based Program, N= 66

$\mathrm{CC}=$ Community College Program, $\mathrm{N}=97$

UNIV= University Based Program, $\mathrm{N}=66$

results of the EF (30.3\%) or from problems discovered through the EF tool (20.2\%).

Educators may have concerns regarding an accommodation, which provides an "unfair" advantage for a student with a disability. An additional concern is that a program may be in violation of ADA regulations if they do not accept a student with a documented disability who does not meet the essential functions of the program. In fact, the study found that that $13.8 \%$ of the programs were encouraged to accept a student although a concern was noted in the EF document. In reality, it may be difficult to define "reasonable accommodation" for a student with a disability, especially in a health care program. It is necessary to protect the health and safety of faculty and patients, as well as students. An accommodation is not reasonable if it presents a direct threat to the health or safety of others or if the disability prevents the student from 


\section{RESEARCH AND REPORTS}

providing appropriate quality care. Also, an accommodation is not reasonable if it results in a significant change to the components of the curriculum. ${ }^{6}$

Another concern is the inability of the student to perform in the clinical setting or as a health care professional once employed. Perhaps reasonable accommodations in the academic setting cannot be equated during the clinical experience or in the work place. As educators, it is our goal to prepare qualified entry level laboratory professionals to practice in the clinical or anatomical laboratory settings upon graduation. However, it is not the responsibility of educators to ensure that students in our programs can perform essential functions in the work place once hired. Only $18.0 \%$ of the participants correctly responded to this question.

Negative student behaviors can affect the student's performance in the classroom and in the clinical rotation. Affective performance, as documented through objectives and evaluations, is an integral component of education and is a required curriculum component for accreditation. It is important for educators to evaluate the student's attitudinal performance and to be knowledgeable of appropriate resources for the student. Study results revealed that although EF instruments are distributed in almost all responding programs, issues with student performance related to essential functions, physical assessment, and behavior led to students being placed on probation and removed from programs. Our study showed that in NAACLS approved and accredited programs, $42 \%$ of the respondents had concerns with inappropriate behavior and that almost one-third reported an increase in such behaviors in the last five years. Interestingly, there was no distinction in respondents based on their years of experience as an educator. Also, almost half of the program respondents stated that they had at least one concern with inappropriate behavior that would lead to aggressive behavior or violence.

Study limitations include that this was a self-report of data that could be affected by the subjective nature of some of the questions. Some of the questions may not have been answered by some of the respondents because there was no suitable response. For example, questions referring to a disabilities office could not be answered by those whose institution lacks such an office. Because this was a descriptive study with reporting of categorical data, inferences cannot be made.

Additional studies might probe the utilization of essential functions and student behaviors in other allied health programs to determine if our results are unique to laboratory education. It would also be useful to determine how student retention and graduation rates are affected by students who are removed from laboratory programs based on essential function or behavioral concerns.

\section{CONCLUSIONS}

This study investigated the perceptions of program directors of NAACLS approved and accredited programs regarding essential functions, students with disabilities, and student behaviors. While most programs were aware of the need for EF documents, many were not aware of the association with $\mathrm{ADA}$ regulations. Additionally, although almost all programs have an EF document, it seems to be viewed as an accreditation requirement and not an active instrument to evaluate student admission and progression through the programs. If students are not aware of what is required and if program directors are reluctant to proactively apply the EF tool, students may have to be subsequently removed from the program. In our survey, almost all ( $95.5 \%$ ) programs use an EF tool, 94.4\% document receipt of the EF tool by the student, and $83.1 \%$ review and discuss concerns with the applicant. However, almost one-third (31.3\%) of the respondents indicated that a student enrolled in their program was advised to seek another program based on concerns related to essential functions. Also, in $21.2 \%$ of the programs, a student was removed based on problems in performance of tasked outlined in the EF document. Though ensuring that students in our programs can perform essential functions in the work place once hired, is not an ADA requirement, $82.0 \%$ of the respondents feel that educators have that responsibility.

Student retention and graduation rates are important components of all outcomes-based program assessment. This becomes particularly significant when college and hospital administrators justify the expense of laboratory education programs. Engaging students actively in the essential function requirements of a program can enhance their chances of success if they are fully 


\section{RESEARCH AND REPORTS}

cognizant of the physical, psychomotor, psychological, and behavioral expectations.

Programs have successfully instructed and graduated students with a variety of disabilities, and faculty are comfortable referring students for academic, behavioral and medical services. It is important for educators to link the requirements of the ADA with those of accrediting agencies so that programs can provide applicants and students with legitimate expectations.

\section{REFERENCES}

1. Fritsma GA, Fioirella BJ, and Murphy M. Essential requirements for clinical laboratory science. Clin Lab Sci. 1996;9(1):40-3.
2. United States Department of Justice [Internet]. Washington: Americans with disabilities act as amended [Updated 2009 March 25; cited 2010 Feb 10]. Available from: http://www.ada.gov/pubs/ada.htm.

3. Caruana, L. Essential functions. NAACLS News. 2000;76:12-3.

4. Delost M. Essential functions revisited. NAACLS News. 2010;104:8-11.

5. Davidson, S. The Americans with disabilities act and essential functions in nursing programs, Nurse Educator. 1994;19:31-4.

6. Jarrow, JA. What is a reasonable accommodation? Excerpted from Higher Education and the ADA; Issues and Perspectives, Disability Access Information and Support, 1997.

The peer-reviewed Research and Reports Section seeks to publish reports of original research related to the clinical laboratory or one or more subspecialties, as well as information on important clinical laboratory-related topics such as technological, clinical, and experimental advances and innovations. Literature reviews are also included. Direct all inquiries to David $L$ McGlasson MS, MLS, 59th Clinical Research Division/SGRL, 2200Berquist Dr., Bldg. 4430, Lackland AFB TX $78236-$ 9908, david.mcglasson@lackland.af.mil

Clinical Laboratory Science encourages readers to respond with thoughts, questions, or comments regarding these articles. Email responses to westminsterpublishers@comcast.net. In the subject line, please type the journal issue and lead author such as "CLIN LAB SCI SUPPL 24(4) RE DELOST". Selected responses may appear in the Dialogue and Discussion section in a future issue. Responses may be edited for length and clarity. We look forward to hearing from you. 